\title{
Suicide and accidental death at Beachy Head
}

\author{
$S$ J SURTEES
}

\begin{abstract}
During 1965-79, 124 deaths occurred at Beachy Head cliffs. A coroner's verdict of suicide was returned in 58 . The yearly numbers increased during the period along with a reduction in the proportion of suicide verdicts. At least 115 of the deaths were almost certainly suicides, and the most likely cause for the change in the proportion of suicide verdicts was a change of coroner.

The reputation of the place, the publicity given to each suicide, the accessibility of the site, and the lack of preparation required all influence the choice of this method and it may be replacing other ways of suicide locally.
\end{abstract}

\section{Introduction}

Beachy Head is a chalk headland marking the eastern end of the South Downs on the English south coast. Some cliffs overhang with a drop of 165 metres (535 feet), but grassy slopes are found along parts of the cliff face.

Deaths from falling off the Sussex cliffs have been known in legend since the sixth century, and two or three deaths a year have been reported over the past century. More recently the annual number of deaths has increased from an average of 4 in 1965-9, to 13 in $1975-9$, while in 1979 there were 17 . During $1965-9$ there was a verdict of suicide in $65 \%$, compared with $32 \%$ in 1975-9. What is the explanation for these changes; are the deaths mainly accidents or suicides; and, if suicides, why pick Beachy Head?

\section{Facts and figures}

"Beachy Head" is defined as an area of coastal headland from Holywell, on the western end of the Eastbourne sea front, to Birling Gap (figure). The cliff top road runs within $50 \mathrm{~m}$ of the cliffs in some parts and is within $100 \mathrm{~m}$ of the highest cliffs.

A "fall at Beachy Head" includes all bodies found on the cliffs or at the base of the cliffs. The site of a fall (figure) has been taken as where observed or where the body was found or, as in 34 cases, where personal possessions were left behind on the edge of the cliff. Table I shows the age and sex of the victims. Seven of the deaths were definitely, and two almost certainly, accidents-two women (aged 15 and 21 ) and seven boys or men (aged $14,18,19,22,25,41$, and 73). The other 115 deaths were probably suicides, but a suicide verdict was recorded in only 58 (table II).

In 92 there was a clear history of mental illness with depression in 77 (67\% of the suicides). Schizophrenia had been diagnosed in 11 $(9 \%)$. Of those with a history of mental illness, 47 were single (with

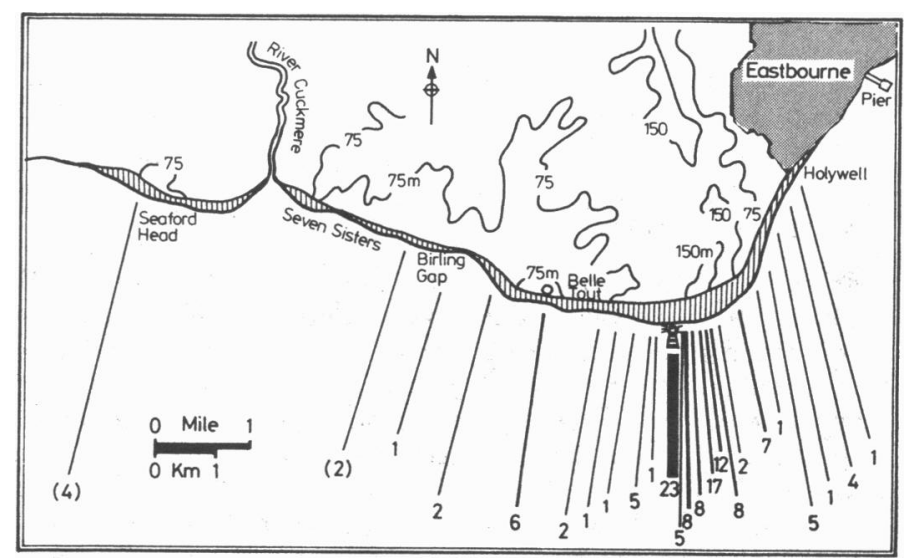

Sites of Beachy Head deaths 1965-79. In three cases the site was uncertain. Falls (in parentheses) are included for completeness but are not considered in the Beachy Head figures.
District General Hospital, Eastbourne, East Sussex BN21 2UD S J SURTEES, MRCPE, FRCPATH, consultant chemical pathologist 
TABLE I-Deaths by age and sex 1965-79

\begin{tabular}{lccccccccc}
\hline & \multicolumn{10}{c}{ Age } \\
\cline { 2 - 10 } & $5-14$ & $15-24$ & $25-34$ & $35-44$ & $45-54$ & $55-64$ & $65-74$ & $\geqslant 75$ & Total \\
\hline $\begin{array}{l}\text { Male victims } \\
\text { Female } \\
\text { victims }\end{array}$ & 1 & 14 & 17 & 8 & 9 & 11 & 3 & 2 & 65 \\
\end{tabular}

TABLE II-Coroners' inquest verdicts 1965-79

\begin{tabular}{|c|c|c|c|c|c|c|c|}
\hline & Total & Suicide & Open & Misadventure & Accidental & $\begin{array}{c}\text { Natural } \\
\text { causes }\end{array}$ & $\begin{array}{c}\text { No } \\
\text { inquest }\end{array}$ \\
\hline 1965 & 3 & 2 & 1 & - & - & - & - \\
\hline 1966 & 6 & 5 & 1 & - & - & - & - \\
\hline 1967 & 1 & - & 1 & - & - & - & - \\
\hline 1968 & 5 & 4 & 1 & - & - & - & - \\
\hline 1969 & 5 & 2 & 2 & 1 & - & - & - \\
\hline 1970 & 4 & 4 & - & - & - & - & - \\
\hline 1971 & 10 & 6 & 3 & 1 & - & - & - \\
\hline 1972 & 6 & 2 & 2 & 1 & - & - & 1 \\
\hline $197 \overline{3}$ & 9 & 6 & 2 & 1 & - & - & - \\
\hline 1974 & 10 & 6 & 3 & - & 1 & - & - \\
\hline 1975 & 16 & 4 & 11 & - & - & 1 & - \\
\hline 1976 & 9 & 1 & 8 & - & - & - & - \\
\hline 1977 & 12 & 4 & 8 & - & - & - & - \\
\hline 1978 & 11 & 4 & 7 & - & - & - & - \\
\hline 1979 & 17 & 8 & 6 & 1 & 2 & - & - \\
\hline
\end{tabular}

two common-law marriages), 34 married, five separated, four widow/ ered, and two divorced. In the remaining 23 probable suicides there was no recorded mental illness, and the main factor was of exogenous stress, varying from impending court proceedings to unrequited love. The date when they had last seen a doctor was known in 61 of the 115 non-accidental cases. Twenty-nine (47\%) had obtained medical advice within one week of suicide and $54(88 \%)$ within three months. Only one of the nine accident victims had seen her general practitioner within the previous three months (for symptoms of allergy).

Deaths at Beachy Head by calendar month and domicile are shown in table III. There is substantial evidence that most victims jump shortly after they are reported missing and within an hour of reaching Beachy Head with more falls on a Friday than any other day of the week.

The domicile of most victims was outside East Sussex, with five from abroad. Only $28 \%$ lived in Eastbourne (this includes contiguous areas such as Pevensey Bay and Polegate) with $39 \%$ in East Sussex (including Eastbourne).

TABLE III-Deaths by calendar month and domicile 1965-79. (Accidents in parentheses)

\begin{tabular}{lcccc}
\hline Month & Total & East Sussex domicile & Outside East Sussex & Others* \\
\hline January & 6 & 2 & 6 & \\
February & 5 & 3 & 3 & \\
March & 13 & 1 & $10(1)$ & 1 \\
April & 3 & 3 & 1 & \\
May & 10 & 4 & $9(2)$ & \\
June & 13 & 12 & $7(1)$ & \\
July & 19 & $8(2)$ & 11 & 1 \\
August & 19 & 4 & $6(1)$ & $1(1)$ \\
September & 11 & 3 & 2 & 1 \\
October & 10 & 6 & 4 & \\
November & 6 & 5 & 4 & \\
December & 9 & & & \\
\hline
\end{tabular}

*For instance, two addresses.

\section{Accident or suicide?}

In most deaths at Beachy Head it is not difficult to decide when and how the victim died. We are left with the questionwas it accident or suicide? Medically we can reach a decision as to suicide on the balance of probabilities; the law, however, demands more rigorous evidence of motivation, and it is generally accepted that the official statistics tend to underestimate the number of suicides. ${ }^{1-3}$

To reach a verdict of suicide the coroner has to satisfy himself that a firm intention was expressed by the deceased." Even when suicide is likely, if the deceased had been drinking the coroner is usually loth to bring in a suicide verdict because the intention may not be clear in a person "under the influence."
Similarly, the coroner will often consider that previous attempts (some perhaps years ago) do not necessarily show the state of mind just before death. It has been suggested that many open verdicts are really suicides, ${ }^{5-7}$ but examination of this premise has produced conflicting evidence. ${ }^{8-10}$ All coroners aim at consistency and accept that it is their duty not to presume suicide $^{11}$; on the other hand, each case has its own set of circumstances and it would be exceptional if the interpretation was exactly the same from coroner to coroner or from year to year. ${ }^{12}$

Undoubtedly there are differences in cultural approach, procedure, and interpretation from country to country. ${ }^{13-15}$ For example, in Scandinavia presumption of suicide is not unusual, and whereas over $90 \%$ of deaths referred to HM coroner have a postmortem examination only $40 \%$ of similar cases are examined in Western Germany. ${ }^{16}$ Not surprisingly, therefore, the reported incidence of suicide varies from 40 per 100000 population in Hungary to two per 100000 in Greece. For this study, being seen to jump was sufficient to presume suicide. Other factors often associated with suicide were also taken into account and each case history was analysed.

The factors used to build up a suicide profile $^{17}$ were both general and those applicable only to deaths at Beachy Head. The general ones included leaving a suicide note; previous suicide attempts; history of mental illness; recent severe emotional upset; the single marital state in an adult; a medical consultation, probably for psychiatric reasons, in the previous three months; and others such as having a "high-risk" occupation. The local factors included being seen to jump or push off; suspicious behaviour on the cliff edge; leaving personal possessions on the cliff top; family history of suicide at Beachy Head; death within 14 days of a fatality at Beachy Head; a domicile outside East Sussex; and others such as taking a taxi straight to Beachy Head from a psychiatric hospital.

All deaths presumed a suicide had at least three factors present and some of the deaths (many with open verdicts) had seven or eight.

At least one previous suicide attempt had been made by 32 victims, ${ }^{18}$ and in $21(65 \%)$ suicide verdicts were returned. Of 10 known to have threatened (but not attempted) to commit suicide, five had suicide verdicts. During 1965-9 seven had attempted or threatened suicide and all had suicide verdicts. In $1970-4$ of 15,12 had suicide verdicts $(80 \%)$. The 20 in $1975-9$ had eight suicide verdicts $(40 \%)$.

As to the local suicide factors, 32 victims were seen to jump, or fall, or drive over. Twenty suicide verdicts $(62 \%)$ were returned. Of 16 in $1965-74$, there were 13 suicide verdicts returned $(81 \%)$ whereas of 16 in 1975-9 there were seven (43\%).

Behaving suspiciously at the cliff edge included such behaviour as drinking half a bottle of whisky while standing on the very edge or waving away holidaymakers on the beach below. Of 19 known to have behaved in this way, there were 13 suicide verdicts $(68 \%)$. During 1965-74 there were 11 instances with 11 suicide verdicts, but of eight in 1975-79, there were two suicide verdicts. Leaving possessions behind on the cliff top is a characteristic behaviour of the suicidal patient. A typical story from an observer of a fall was, "saw him near the edge, then walk back a short distance. He divested himself of coat and gloves, placed one on top of the other, walked back to the cliff, and jumped immediately." Dr A C Sommerville, a former coroner, once remarked that no woman just intent on a stroll along the cliff top would place her handbag down on the edge and go for a walk. Of the 20 who left possessions on the cliff top in 1965-74 there was a suicide verdict in $17(85 \%)$; of the 14 in $1975-9$ six $(42 \%)$ had a suicide verdict.

Thus examination of the case histories shows that the vast majority had a significant suicide profile even when a verdict other than suicide was returned. There has also been an obvious change in the ratio of suicide/open verdicts (and table II shows that this occurred from 1975 onwards) that was independent of the factors associated with suicide. In 1974 the average number of suicide profile factors per case was 4.3 and in 1975 it was $5 \cdot 1$, so that, if anything, in 1975 a greater proportion of suicide 
verdicts could be expected. In fact, in 1974 there were six suicide verdicts and three open compared with four suicide verdicts and 11 open in 1975. Although the suicide profile of the victims has not changed, there has possibly been a shift in the interpretation of the law. The passage of the Suicide Act in 1961, which abolished suicide as a crime, did not remove the religious and social stigma of suicide and several verdicts of suicide have been quashed on appeal by relatives, the courts emphasising that unless a clear intention is expressed a verdict of suicide must not be returned. ${ }^{1920}$ In December 1974 the Lord Chief Justice quashed a verdict of the local coroner (only recently appointed) in the case of a man who fell from a cliff. ${ }^{21}$

\section{Why choose Beachy Head?}

A fall of 30 metres (100 feet) on to any firm surface is sufficient to cause death. A jump from a third floor on to a concrete surround should ensure success. Ample means are thus available, but would-be suicides show a tendency to emulate a successful method, and the imitative suicide is a well-known phenomenon.

Sainsbury ${ }^{22}$ stated that newspaper reports encouraged suicides, and Barraclough ${ }^{23}$ has shown a significant association between inquest reports on suicides in a local paper and subsequent suicide in men under 45 years of age. One of the victims at Beachy Head, a 56-year-old man in hospital recovering from a suicide attempt by overdose, read a newspaper report about suicides at Beachy Head and remarked, "fancy putting something like that in the paper for people like me to see." Two weeks later he jumped to his death. Deaths at Beachy Head are well publicised. Over the 15 years the number of victims from outside East Sussex, especially men, has gradually increased (table IV). Comparison of the suicide methods used in 30 cases investigated by a local histopathologist in 1968, and part 1969 (Dr D C Taylor), and in 1979 (Dr D C Shove) shows (table V) that the number of cases at Beachy Head had doubled, with a reduction in the use of guns and coal gas (North Sea gas conversion 1973).

Fashions in suicide methods amounting to "epidemics" have been documented since $1792,,^{24-26}$ and the death of a famous actress in August 1962 was followed by an increase in the number of suicides in Los Angeles over the ensuing month. The suicide rate for the year, however, was not increased, suggesting that such events influence those considering suicide as to the time and method but do not represent the deaths of people who otherwise would not have taken their own life. Surtees et al in $1976^{27}$ confirmed that deaths at Beachy Head occurred in clusters and suggested that the publicity that surrounded such a

TABLE IV-Deaths (with domicile* and sex) over five-year periods

\begin{tabular}{cccccc}
\hline & \multicolumn{3}{c}{ Male } & & \multicolumn{2}{c}{ Female } \\
\cline { 2 - 3 } \cline { 5 - 6 } \cline { 5 - 6 } & East Sussex & Outside & & East Sussex & Outside \\
\hline $1965-9$ & 2 & 5 & & 8 & 5 \\
$1970-4$ & 4 & 15 & & 8 & 9 \\
$1975-9$ & 15 & 23 & & 12 & 15 \\
\hline
\end{tabular}

*Excludes three with both London and Eastbourne addresses.

TABLE $\mathrm{v}-$ Methods of suicide in the Eastbourne district (presenting to one histopathologist)

\begin{tabular}{lcc}
\hline Method & 1968 & 1979 \\
\hline Beachy Head & 5 & 11 \\
Overdose & 12 & 13 \\
Drowning & 4 & 2 \\
Hanging & 0 & 1 \\
Jumping (from building) & 1 & 1 \\
Jumping (in front of lorry) & 0 & 1 \\
Shotgun & 3 & 0 \\
Coal gas & 2 & 1 \\
Plastic bag over face & 1 & 0 \\
Car exhaust & 1 & 0 \\
Multiple (drugs/drowning/bag) & 1 &
\end{tabular}

death reinforced the stimulus for those individuals intent on suicide to try where they know others have succeeded.

Inquiry as to the incidence of deaths and suicides at other cliffs shows that there is no comparable number of either deaths or suicides. On the cliffs at Dover, which are structurally similar and are at least as famous as Beachy Head, there was only about one suicide a year over the 22 years from 1956. The Dover cliffs are less accessible, whereas it is not an arduous walk from Eastbourne to Beachy Head. Other cliffs, either of a similar nature or associated with holiday resorts, also have a much lower incidence. For example, at Torbay there were 14 deaths from 1966 to 1976 with three probable suicides (two suicide verdicts) and the rest were accidents while climbing or bird nesting.

For some would-be suicides there is an attraction to an "active" method of suicide such as jumping. Active methods are usually associated with male suicides, but jumping from a height is the only active method used substantially by women. ${ }^{28}$ In the 32 cases observed to fall witnesses were able to describe precise detail for 16. Of nine women, five were said to "slide off" ("pushed herself over with her back to the sea") and four jumped over ("she said, 'I am going over' and then jumped"). In comparison, of seven men, five jumped ("I saw a young man running to the cliff edge. He did not stop but did an elegant dive") and only two slid off.

Table III shows that most deaths at Beachy Head were in the summer months and that April, which has a peak of suicides from other causes, ${ }^{29} 30$ had least. Possibly there is a strange attraction in the beauty of the summer scene, but the main reason for the excess of suicides in summer appears to be that Beachy Head is even more accessible in the summer for both locals and visitors. The weather is less inclement and the bus service more frequent.

Finally, in this attempt to discover what makes people choose Beachy Head it is possible to ask some of the "victims"namely, four women who survived suicide attempts there. None chose an area of overhanging cliff, but a 72 year old survived a sheer drop of $25 \mathrm{~m}$ on to a grassy ledge and a 30 year old fell some $90 \mathrm{~m}$ over steep slopes only to be caught in shrubs and brambles, which acted as arrester wires, still $45 \mathrm{~m}$ above the shore. $^{31}$ Interviewed afterwards about the attempted suicide, two said that they would try again and a third has had to be persuaded not to return to Beachy Head.

One, an Eastbourne woman suffering from a psychiatric illness, believed that Beachy Head was always available, presumably in the sense that no artificial aids, such as knives or ropes, were required and there was no need for preparatory delay, such as having to save up tablets or prepare the car exhaust. As another said, all you needed to do was to keep walking.

In some cases details have been confirmed or corrected from perusal of the coroners' inquisition by permission of HM coroner. Reliance has also been placed on contemporary accounts by rescue teams and reports in local and national newspapers.

I thank the coroners for the district, Dr A C Sommerville, Mr J S Dodd, and Mr E N Grace for their help and courtesy, which they have extended not only to me but also at all times to the relatives and others who have attended their court. The coroner's officers, PC T Coates and PC M Davey, have been of great help and the co-operation of $\mathrm{Mr} \mathrm{H}$ Homewood, Mr A Homewood, Mr R W Cooper, and Mr J Hoad has been appreciated.

A tribute must be paid to the police, firemen, and coastguards who have rescued and recovered victims from the cliffs, often under dangerous and unpleasant conditions. The recent award of the British Empire Medal to Mr Gary Russell, the local coastguard-incharge, is a measure of our thanks to these brave men.

\section{References}

${ }^{1}$ Legal correspondent. Coroners and suicide. $\mathrm{Br}$ Med $\mathcal{F} 1975$;iii:238-9.

2 Anonymous. While the balance of his mind was disturbed. $\mathrm{Br}$ Med $\mathrm{f}$ $1977 ; \mathrm{i}: 128$.

${ }^{3}$ Anonymous. Accident or suicide? $\mathrm{Br} \operatorname{Med} \mathcal{F} 1977$;ii :212-3.

4 Barraclough BM. Poisoning cases. Suicide or accident? Br $\mathcal{F}$ Psychiatry 1974 ;124:526-30. 
${ }^{5}$ Jacobson S, Bagley C, Rehin A. Clinical and social variables which differentiate suicide, open and accidental verdicts. Psychol Med 1976; 6:417-21.

${ }^{6}$ Barraclough BM. Are the Scottish and English suicide rates really different ? Br F Psychiatry 1972;120:267-73.

7 Bagley C. Correspondence on the validity and meaning of suicide statistics. Sociology 1974;8:313-6.

${ }^{8}$ Barraclough BM, White SJ. Monthly variation of suicide and undetermined deaths compared. Br F Psychiatry 1978;132:275-8.

- Barraclough BM, White SJ. Monthly variation of suicidal, accidental and undetermined poisoning deaths. Br $\mathcal{F}$ Psychiatry 1978;132:279-82.

10 Holding TA, Barraclough BM. Undetermined deaths-suicide or accident ? Br F Psychiatry 1978;133:542-9.

${ }^{11}$ Sainsbury P, Barraclough B. Differences between suicide rates. Nature $1968 ; 220: 1252$

12 Surtees SJ. Suicide prevention by the Samaritans. Lancet 1977;ii:872.

13 Barraclough BM. Differences between national suicide rates. $\mathrm{Br} \mathcal{F} \mathrm{Psy}$ chiatry 1973;122:95-6.

${ }^{14}$ McCarthy PD, Walsh D. Suicide in Dublin. Br $\mathcal{F}$ Psychiatry 1975;126: 301-8.

15 Atkinson MW, Kessel N, Dalgaard JB. The comparability of suicide rates. Br F Psychiatry 1975;127:247-56.

16 World Health Organisation. Suicide and attempted suicide. Public Health Paper No 58. Geneva: WHO, 1974.

17 Anonymous. The suicide profile. Br Med f 1975 ;ii:525-6.
18 Capstick A. Recognition of emotional disturbance and the prevention of suicide. $\mathrm{Br}$ Med $\mathcal{F} 1960 ; \mathrm{i}: 1179-82$

19 Re Davis (dec'd) (1968) 1 QB:82D.

${ }^{20} R v$ Cardiff City Coroner ex parte Thomas (1970) 1 WLR 1475.

${ }^{1}$ Surtees SJ. Tales of Beachy Head. Eastbourne Medical Gazette 1978;2: 71-8.

22 Sainsbury P. Suicide in London. Maudsley Monograph No 1. London: Chapman and Hall, 1955:65.

${ }^{23}$ Barraclough BM, Shepherd D, Jennings C. Do newspaper reports of coroners' inquests incite people to commit suicide? $\mathrm{Br} \mathcal{F}$ Psychiatry $1977 ; 131$ :528-32.

${ }^{24}$ Read CS. The problem of suicide. Br Med F 1936;i:631-4.

${ }^{25}$ Simpson MA. The great suicide epidemic of 1933. World Medicine $1978 ; 13: 77-9$.

${ }^{26}$ Ashton JR, Donnan SPB. Suicide by burning - a current epidemic. Br Med f 1979 ;ii:769-70.

27 Surtees SJ, Taylor DC, Cooper RW. Suicide and accidental death at Beachy Head. Eastbourne Medical Gazette 1976;2:22-4.

28 Capstick A. The methods of suicide. Medico-Legal fournal 1961 ;29:33-8

${ }^{29}$ Wells N. Suicide and deliberate self-harm. London: Office of Health Economics, $1981: 6$

30 Swinscow D. Some suicide statistics. Br Med F 1951 ; i:1417-23.

${ }^{31}$ Surtees SJ. Tales of Beachy Head. Eastbourne Medical Gazette 1980;2: 135-41.

(Accepted 3 November 1981)

\title{
Hepatitis B virus infection in medical and health care personnel
}

\author{
M E CALLENDER, YVETTE S WHITE, ROGER WILLIAMS
}

\begin{abstract}
An analysis of 51 cases of hepatitis $B$ virus infection in health care workers admitted as patients to the liver unit over seven years showed three healthy carriers of hepatitis $B$ virus, seven cases of fulminant hepatic failure, 13 cases of acute hepatitis, six cases of chronic persistent hepatitis, 17 cases of chronic active hepatitis (of whom 11 had cirrhosis), and five cases of hepatocellular carcinoma. To date 11 of these patients have died. Only 15 of the 51 patients had a history of direct occupational exposure and only three patients could recall specific inoculation injuries. In contrast, the source of infection was apparent in 32 of 50 consecutive cases of fulminant hepatic failure or acute hepatitis $B$ in nonmedical staff.

Since specific inoculation injuries are not the usual mode of infection in medical staff and since only a few of the patients who are hepatitis $B$ virus carriers will be detected by selective screening of "high-risk" patients, the overall risk of infection can be reduced only by stricter precautions in the handling of any patient's blood and by the use of hepatitis $B$ virus vaccines for medical staff at high risk.
\end{abstract}

\section{Liver Unit, King's College Hospital and Medical School, London} SE5 8RX

M E CALLENDER, MB, MRCP, honorary senior registrar

YVETTE S WHITE, DIPMLJ, senior medical liaison scientific officer

ROGER WILLIAMS, MD, FRCP, director

\section{Introduction}

Even before the identification of antigens of the hepatitis $B$ virus, homologous serum jaundice was thought to be an occupational hazard in medical staff, ${ }^{1}$ and the recent studies using antibody to hepatitis B surface antigen (anti-HBs) as a marker of previous exposure to hepatitis $B$ virus show without doubt that medical staff are more often exposed than the general population. The highest prevalence of anti-HBs is among surgeons and pathologists, although nurses, laboratory staff, workers in renal units, blood procurers, and dentists are also affected. ${ }^{2-4}$ Prevalence increases with age, but among medical staff the most rapid rise is in the early years after entering clinical work. ${ }^{2}$ Outbreaks of acute hepatitis B in renal and oncology units ${ }^{56}$ and in relation to emergency surgery ${ }^{7}$ provide further evidence that medical staff can acquire hepatitis $B$ virus infection from patients.

The availability of specific immune globulin for use after incidents of accidental inoculation and the very recent introduction of hepatitis $B$ virus vaccines ${ }^{8}$ have opened new approaches for prevention, and because of this we decided to review our experience of liver disease related to hepatitis B virus among health care workers with particular reference to the time and source of infection, the findings being compared with 50 consecutive cases of acute type B hepatitis in non-medical staff.

\section{Series of patients}

The series of 51 patients comprised 39 men and 12 women referred to the liver unit in the past seven years in whom hepatitis B virus infection was proved. Serum was examined for HBsAg and anti-HBs 